\title{
ANALISIS PERFORMANSI REFRIGERATOR MEDIUM TEMPERATUR (MT) DENGAN PENGATURAN KELEMBABAN
}

\author{
I Dewa M.C. Santosa, I Gede N. Suta Waisnawa, Made Ery Arsana \\ Jurusan Teknik Mesin , Politeknik Negeri Bali \\ Jalan Kampus Bukit Jimbaran, Kuta Selatan, Badung, Bali, 80363 \\ e-mail : idmcsantosa@pnb.ac.id
}

\begin{abstract}
Indonesia is one of the largest producers of horticultural, especially tropical fruits and vegetables. Because of tropical country, the outdoor temperature and humidity are relatively high, so that the horticultural products are decay very fast. In several developing countries including Indonesia, as much as $40 \%$ of fruits and vegetables from total production are becoming waste due to lack of refrigerated. The existing medium temperature refrigerator (MT refrigerator) system has temperature controler only, so it still can not maintain the quality of the products. This research is aimed to get optimization of MT refrigerator system with the best option of humidifier technology and efficient operation. The research method will be conducted by re-design of existing medium temperature refrigerator system technology and will be given an innovation of an artificial and natural humidifier with precision setting system, then commenced test will be done, followed by performance test of the system. The results show that the performance of the system using mechanic humidifier is higher approximately 3\%-5\% than the natural one. In summary, the research has been obtained more effective humidity system, however for natural humidifier need to be more performance test especially in the rural area which has higher humidity and lower ambient temperature.
\end{abstract}

Keywords: refrigerator, medium temperature, humidifier, fresh vegetable, fresh fruit

\begin{abstract}
ABSTRAK
Indonesia merupakan salah satu produsen terbesar untuk produk holtikultura terutama buah-buahan dan sayuran. Namun di lain pihak, karena temperatur dan kelembaban udara lingkungan sangat tinggi maka produk-produk tersebut sangat cepat mengalami pembusukan. Di negara berkembang seperti Indonesia, sebanyak $40 \%$ buah dan sayur dari produksi totalnya terbuang dan menjadi sampah (waste) karena kurangnya pendinginan. Sistem refrigerator medium temperatur (MT) yang ada pada saat ini baru mempunyai pengaturan suhu saja sehingga masih mempunyai kelemahan yang tinggi untuk menjaga kualitas produk-produk yang disimpan. Tujuan dari penelitian ini adalah untuk mendapatkan optimasi sistem refrigerator MT dengan pilihan teknologi humidifier dan pengoperasian yang efisien/hemat. Metode penelitian dilakukan dengan re-desain teknologi sistem refrigerator medium temperatur yang sudah ada dan akan di berikan inovasi berupa humidifier buatan dan alami dengan sistem pengaturan yang presisi, kemudian sistem akan dilakukan commencing test, dilanjutkan dengan performance test dari sistem. Analisis terhadap performasi mesin refrigerator didapatkan bahwa dengan mengunakan humidifier mekanik performansi sistem lebih tinggi berkisar 3\%-5\% pada lingkungan pengujian di Lab Refrigerasi-Politeknik Negeri Bali. Dengan demikian hasil dari penelitian ini sudah didapatkannya produk teknologi tepat guna berupa refrigerator medium temperatur dengan pengaturan suhu dan kelembaban yang efisien dan hemat listrik.
\end{abstract}

Kata kunci : Sistem refrigerator, medium temperatur, humidifier, sayur, buah segar.

\section{PENDAHULUAN}

Mengingat negara kita adalah tropis maka laju pembusukan (spoilage rate) produk holtikultura sangat tinggi jika tanpa pendingin. Kurangnya pendinginan pada sayur dan buah segar secara umum menimbulkan permasalahan lain yaitu: i) durability product rendah (rata-rata 3 hari), ii) kualitas produk rendah (hygienis , tercemar bakteri dan pembusukan), iii) supplai tidak kontinu ${ }^{[14]}$. Dampak yang nyata terasa pada masyarakat adalah jumlah pasokan yang kurang dan harga sangat fluktuatif yang menjadi sangat tinggi pada saat permintaan naik seperti pada saat hari raya nasional, tentunya 
hal ini sangat merugikan petani maupun konsumen ${ }^{[10]}$.

Sistem refrigerator medium temperatur dalam penelitian ini didefinisikan merupakan suatu sistem mesin pendingin dengan rentang temperatur pendinginan yang bias diatur dalam ruang sampai dengan $-5^{\circ} \mathrm{C}$. Hal ini juga berdasarkan data base penyimpanan sayur dan buah segar rata-rata $10^{\circ} \mathrm{C}-$ $15^{\circ} \mathrm{C}$. Namun sistem juga sangat perlu untuk diatur kelebabannya terintergrasi dengan temperatur ruangan refrigerator. Kelembaban relatif (RH) yang diinginkan adalah berkisar 75\% - 90\% sesuai dengan jenis buah dan sayuran yang disimpan ${ }^{[12]}$.Inovasi penting yang dilakukan pada sistem refrigerator ini berupa sistem pengaturan kelembaban yang akan diteliti dua sistem pengatur kelembaban yang berbeda yaitu dengan sistem alami dan sistem mekanik.

Untuk produk sayuran dan buah maka penyimpanan pasca panen sangat penting karena berkaitan dengan laju kerusakan (deterioration) yang disebabkan oleh perubahan karena proses biochemical dan karena mikroorganisme ${ }^{[1]}$. Temperatur sangat berperan dalam dalam hal ini. Dalam penyimpanan produk-produk holtikultuta (medium temperature), tentunya spesifikasi/karakteristik masing-masing produk memerlukan kondisi yang berbeda-beda. Secara umum untuk penyimpanan sayuran dan buah segar berkisar antara $0^{\circ} \mathrm{C}$ sampai dengan $15 \quad{ }^{\circ} \mathrm{C}$ dengan kelembaban relatif $(\mathrm{RH})$ berkisar 90 sampai 95\% dan pasca panen dapat bertahan antara 3-6 minggu. Bahkan untuk industri makanan yang sebelumnya menyimpan pada temperatur diatas $0^{\circ} \mathrm{C}$, kini sudah menurunkan temperaturnya menjadi antara $-18^{\circ} \mathrm{C}$ sampai $-35^{\circ} \mathrm{C}$ dengan tujuan mengurangi atau memperlambat kerusakan phisik, kimia dan microbiologi ${ }^{[13]}$. Sedangkan beberapa produk holtikultura asli Indonesia misalnya buah durian, manggis, duku maupun cabai diperlukan temperatur rata-rata $10^{\circ} \mathrm{C}-15^{\circ} \mathrm{C}$ pada kelembaban realtif $90 \%-95 \%$ untuk masa penyimpanan 2 minggu sampai 1 bulan dan tentunya dapat ditingkatkan waktu penyimpanannya dengan menurunkan temperatur yang lebih rendah ${ }^{[6]}$.

Kualitas produk holtikultura pasca panen dijaga dengan sistem penurunan temperatur dan menjaga kelembaban. Dan didapatkan bahwa dengan penurunan temparatur sampai dengan $0^{\circ} \mathrm{C}$ dan kelembaban $90 \%$ dapat meningkatkan durability produk dan dapat tetap menjaga kualitas produk (texture, nutrition, aroma and rasa) dan juga didaptkan bahwa kelerlambatan waktu pendinginan pasca panen akan menurunkan kualitas dengan cepat [13], [7], [1], [3] .

Paull (1999). Delele et al , (2009) meneliti optimasi sistem humidifier dan mendapatkan bahwa efisiensi humidifier dipengaruhi oleh panjang dari deflector, jumlah nosel, dan durasi dari humidifikasi. Untuk performansi terbaik disarankan panjang deflector $0,8 \mathrm{~m}$, siklus interval humidifikasi 1,5 min on dan 2 min off . Dengan bantuan Program CFD, ${ }^{[4]}$ menunjukkan gradasi distribusi kelembaban dan temperatur dalam ruang refrigerator, dimana ada perbedaan berkisar $1^{\circ} \mathrm{C}$ untuk distribusi suhu dan untuk kelembaban ada perbedaan distribusi sampai dengan sekitar 8\%, ini menunjukkan bahwa humidifier perlu optimasi untuk mencapai efisiensi yang tinggi.

\section{METODE PENELITIAN}

Penelitian ini merupakan penelitian experimental dengan tahapan utama adalah re-desain, rancang bangun, uji commissioning dan uji performance sistem refrigerator medium temperatur dengan pengaturan suhu dan kelembaban. Data data untuk kebutuhan redesain didapat dari literatur dan penelitian yang sudah dilaksanakan 
sebelumnya. Pengujian juga dilakukan terhadap produk buah dan sayuran yang disimpan terhadap kualitas dan lama penyimpanannya.

Gambar 1(a) menjelaskan diagram skematik dari prototipe yang diredesain. Proses pembuatan mengikuti prosedur produksi yang standar. Sistem kontrol kelembaban dan temperatur dirancang sesuai dengan kebutuhan sistem humidifier yang diinginkan. Untuk humidifier alamiah menggunakan timer yang dapat di set durasi hidup dan frekuensi operasional blowernya. Sedangkan untuk humidifer mekanik dikontrol dengan control humidifier digital dengan tambahan kontaktor untuk on-off dari peralatan humidifier, seperti ditunjukkan pada Gambar 1 (a) dan 1(b) berikut ini.

Prototipe refrigerator MT tersebut dibuat di Lab Refrigerasi - Politeknik Negeri Bali. Prorotipe mesin pendingin dimodifikasi untuk mendapatkan kelembaban berkisar 60\% - 95\% . Instrumentasi, kontrol dan alat ukur dan data logger dilengkapi untuk mesin pendingin dan produknya yaitu termokopel, sensor kelembaban / higrometer, power meter - ampere meter seperti ditunjukkan pada Gambar 2 berikut.

Temperatur (T), kelembaban (RH) serta waktu penyimpanan dan ini merupakan hal yang sangat penting untuk menjaga kualitas produk. Namun optimasi penyimpanan sangat dibutuhkan sehingga nantinya harga produknya dapat bersaing di pasaran. Analisis ini dilakukan berdasarkan hasil observasi leksperimen dan juga akan dikonfirmasi dengan standard ASHRAE (American Society of Heating, Refrigerating and Air Conditioning Engineers). Untuk uji performansi mesin akan dihitung dengan bantuan Program EES dan akan dianalisis dengan persamaan thermodinamika dan thermofluid.

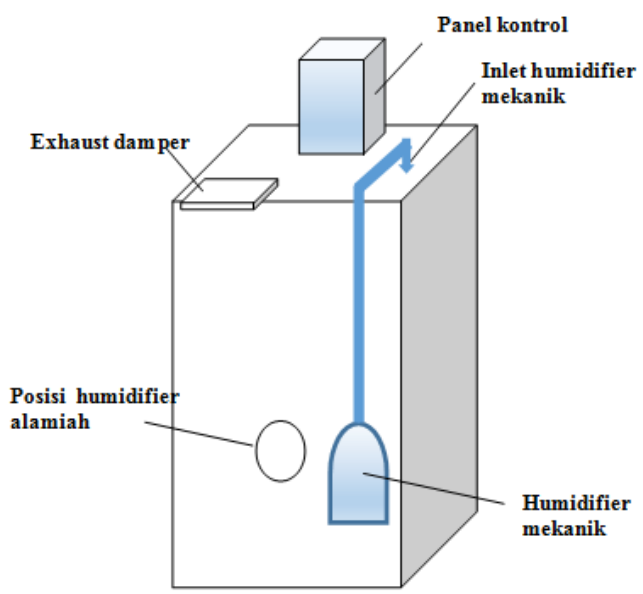

(a)

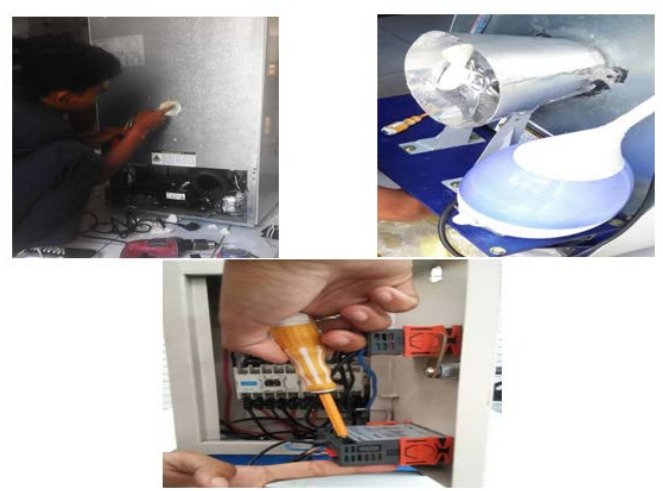

(b)

Gambar 1. Re-desain prototipe refrigerator temperatur medium (a) diagram re-desain, (b) photo peralatan control kelembaban

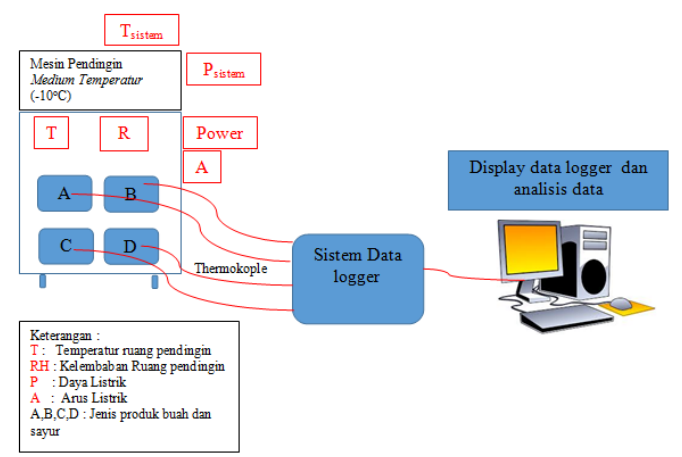

Gambar 2. Diagram peralatan eksperimen refrigerator temperatur medium

\section{HASIL dan PEMBAHASAN}

Kondisi penyimpanan berupa suhu $\left({ }^{\circ} \mathrm{C}\right)$ dan kelembaban (\%) berbagai jenis produk sayur dan buah-buahan segar telah dikumpulkan dari berbagai sumber (ASHRAE,2014; Gogou et al,2015, Hasbie et al, 2015) . Didapatkan kondisi 
pendinginan/penyimpanan rata-rata berkisar $5-13^{\circ} \mathrm{C}$ dan dengan kelembaban 65\%-95\%. Dengan demikian rancangan refrigerator MT ini akan disesuaikan dengan database ini. Seperti ditunjukkan pada Tabel 1.

Berdasarkan hasil uji komisioning didapatkan bahwa mesin dapat dijaga kelembabannya sampai dengan $98 \%$ dan temperatur sampai dengan $-5^{\circ} \mathrm{C}$. sehingga dari krakteristik penyimpanan sayur dan buah segar yang minimal suhu penyimpanannya adalah $5^{\circ} \mathrm{C}$ dan kelembaban maksimal $98 \%$ prototipe mesin refrigerator dapat memenuhi uji performance dari produk yang akan diujikan.

Dengan menerapkan metode diatas didapatkan perhitungan performansi dari sistem dengan kondisi operasional yang terdiri dari : operasional humidifier mekanik dengan dan tanpa beban serta operasional humidifier alamiah tanpa dan dengan beban. Dari hasil yang didapatkan bahwa dengan operasional alamiah, performansi sedikit menurun berkisar 3\%-5\% dengan penggunaan humidifier mekanik, hal ini disebabkan karena fresh air yang dialirkan masih dengan kondisi temperatur yang relatif tinggi (data diambil dalam kondisi udara luar berkisar $29^{\circ} \mathrm{C}$ dan kelembaban $78 \%$. Sedangkan dengan humidifier mekanik kelembahan yang ditambahkan dalam bentuk steam/uap sehingga panas latennya tetap konstan (tidak ada kehilangan panas laten) dan sistem lebih sedikit mendapatkan beban pendingin.

Untuk meningkatkan performansi sistem dengan menggunakan humidifier alamiah direkomendasikan pengunaannya di lingkungan yang lebih dingin dan lebih lembab serta di pedesaan/pegunungan sangat efektif untuk digunakan. Jika direncanakan sebuah atau suatu cold room berada di sentra-sentra pertanian di pedesaan maka humidifier alamiah ini akan sangat efektif untuk diterapkan.

\section{KESIMPULAN}

Dalam pengembangan prototipe mesin pendingin (refrigerator temperatur medium) ini sudah didapatkan hasil berupa efektifitas penggunaan humidifier alamiah ataupun dengan mekanik. Dengan humidifier ini telah mampu meningkatkan kelembaban ruangan pendingin. Berdasarkan analisis yang lebih mendetail untuk kondisi lingkungan yang diujikan (di Lab Refrigerasi-Politeknik Negeri Bali), humidifier mekanik lebih efektif untuk diterapkan karena dapat menjaga performansi sistem lebih tinggi. Namun untuk kondisi lingkungan yang lebih dingin dan lembab seperti di pedesaan tetap memerlukan penelitian lebih lanjut untuk penerapan sistem alamiah yang lebih efektif.

\section{DAFTAR PUSTAKA}

[1] ASHRAE, 2014. ASHRAE Hand book of Refrigeration. ASHRAE, Inc., Atlanta.

[2] BPS Propinsi Bali tahun 2017, available at www.bps.go.id

[3] Coulomb D., 2008, Refrigeration and cold chain serving the global food industry and creating a better future: two key IIR challenges for improved health and environment, Food Science and Technology. 19: 413-417.

[4] Delele M.A, Schenk A., Ramon H., Nicolaï B.M., Verboven P. 2009, Evaluation of a chicory root cold store humidification system using computational fluid dynamics, Journal of Food Engineering. 94 : 110-121. 
[5] Gogou E., Katsaros G., Derens E., Alvarez G., Taoukis P.S., 2015, Cold chain database development and application as a tool for the cold chain management and food quality evaluation, International Journal of Refrigeration. 52: 109121.

[6] Hasbi, Saputra D., Juniar, 2005, Masa Penyimpanan Buah Manggis (Garcinia Mangostana L.) pada Berbagai Tingkat Kematangan , suhu dan kemasan, Jurnal Teknologi dan Industri Pangan. Vol.XVI No.3.

[7] Laguerrea O., Hoanga H.M., Flick D., 2013, Experimental investigation and modelling in the food cold chain: Thermal and quality evolution, Food Science and Technology, 29: 87-97

[8] Nahman A., Lange W.D., 2013, Costs of food waste along the value chain: Evidence from South Africa, Waste Management. 33:24932500.

[9] Paull R. E., 1999, Effect of temperature and relative humidity on fresh commodity quality, Postharvest Biology and Technology. 15 : 263-277.

[10] Rafani I., 2014, Strategic Plan of Indonesian Ministry of Agriculture: 2015-2019, Indonesian Center for Agriculture Socio Economic and Policy Studies (ICASEPS), Ministry of Agriculture, Indonesia.

[11] Rediersa H., Claesa M., Peetersa L., Willemsa K.A., 2009, Evaluation of the cold chain of fresh-cut endive from farmer to plate, Postharvest Biology and Technology. 51: 257-262.

[12] Suta W., Santosa I D M C, Sunu, 2018, Model Development of Cold Chains for Fresh Fruits and Vegetables Distribution: A Case Study in Bali Province, Journal of Physics:conference series, 953 (1), 012109
[13] Tassou S.A, De-Lille G., Ge Y.T., 2010, Food transport refrigeration Approaches to reduce energy consumption and environmental impacts of road transport, Applied Thermal Engineering. 29: 14671477.

[14] Tassou S.A, Lewis J.S., Ge Y.T., Hadawey A., Chaer I., 2015, A review of emerging technologies for food refrigeration applications, Applied Thermal Engineering. 30:263-276. 
I Dewa M.C. Santosa, I Gede N. Suta Waisnawa dan Made Ery Arsana, Analisis Performansi Refrigerator.

\section{LAMPIRAN}

Tabel 1. Karakteristik penyimpanan buah dan sayur segar

\begin{tabular}{lllll}
\hline No. & Produk & $\begin{array}{l}\text { Temperatur } \\
\left({ }^{\circ} \mathrm{C}\right)\end{array}$ & $\begin{array}{l}\text { Kelembapan } \\
(\%)\end{array}$ & $\begin{array}{l}\text { Ketahanan waktu } \\
\text { setelah panen }\end{array}$ \\
\hline 1 & Asparagus & 5 & $90-100$ & $2-3$ minggu \\
2 & Cabai keriting & $5-10$ & $85-95$ & $2-3$ minggu \\
3 & Cabai besar & $5-10$ & $85-95$ & $2-3$ minggu \\
4 & Kol & 5 & $95-100$ & $3-6$ minggu \\
5 & Tomat & $10-12$ & $90-95$ & $2-5$ minggu \\
6 & Sawi & 5 & $98-100$ & $2-4$ minggu \\
7 & Wortel & 5 & $98-100$ & $3-6$ bulan \\
8 & Paprika & $7-10$ & $95-98$ & $2-3$ minggu \\
9 & Bawang Merah & 5 & $65-70$ & $1-8$ bulan \\
10 & Bawang Putih & 5 & $65-70$ & $6-7$ bulan \\
11 & Jeruk & 12 & $85-90$ & $1-6$ bulan \\
12 & Strawberi & 5 & $90-95$ & 4 hari \\
13 & Mangga & 13 & $85-90$ & $2-3$ minggu \\
14 & Manggis & 13 & $85-90$ & $2-4$ minggu \\
15 & Durian & 6 & $85-90$ & $5-8$ minggu \\
16 & Pisang & $14-16$ & $90-95$ & $1-4$ minggu \\
17 & Anggur & 5 & $90-95$ & $2-8$ minggu \\
18 & Nangka & 12,5 & $85-90$ & $2-4$ minggu \\
19 & Melon & 10 & $85-90$ & $3-4$ minggu \\
20 & Papaya & $10-13$ & $85-90$ & $1-3$ minggu \\
21 & Nanas & $7-12,5$ & $85-90$ & $2-4$ minggu \\
\hline
\end{tabular}

Sumber: ASHRAE (2014);Gogou (2015), Hasbie (2005)

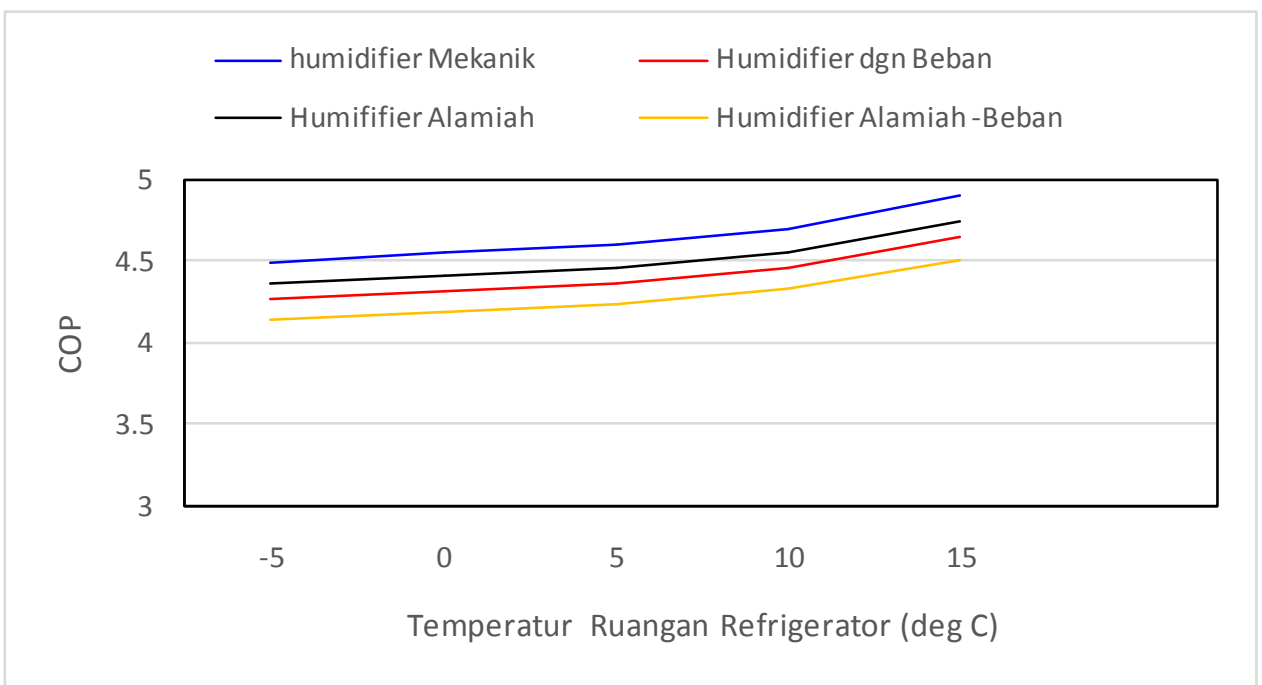

Gambar 3. Variasi performansi sistem dengan operasional humidifier mekanik dan alamiah 